\title{
Physics of Tsunami: Generation, Propagation and Rise of the Ocean
}

\author{
Swapan Kr. Barman \\ Formerly Associate Professor of Mathematics \\ Maulana Azad College, Kolkata, India.
}

\begin{abstract}
Mechanisms that work underneath the generation of tsunamis, their propagation over the ocean, and the enormous rise of the ocean surface as tsunamis approach coastlines, are examined. Physics of these phenomena, with special emphasis on the great rise of the ocean, are investigated.
\end{abstract}

Keywords: Tectonic plate, earthquake, tsunami, shallow water wave, transverse and longitudinal sea water waves, energy.

\section{INTRODUCTION.}

'Tsunami' (pronounced as 'soo-nah-mee') is a Japanese word. In Japanese, 'tsu' means 'harbour' and 'nami' means 'wave', so that 'tsunami' means "harbour wave". This nomenclature had been coined because these waves, while go almost unnoticed on the deep ocean, rush with their dreadful appearance on shallow water near the coastline, beaches and harbours.

A tsunami is a series (train) of waves of extremely long wavelength and long period propagating over the ocean, generated by a massive impulsive disturbance that suddenly displaces a very large volume of water. Catastrophic underwater events like submarine earthquakes, landslides, volcanic eruptions, man-made undersea nuclear explosions, and even the collision of cosmic bodies (objects from outer space), such as meteorites, asteroids, etc. with the Earth, can create tsunamis.

The wavelength and period of the tsunami depend on the nature and dimensions of the generating mechanism. If the tsunami is produced by a violent underwater earthquake over a vast area of the seafloor, both the initial wavelength and period become long. If, on the other hand, the tsunami is caused by a local landslide, the initial wavelength and period of the waves become comparatively short. 
The wavelength of a tsunami travelling on the open ocean surface, may be of the order of 150 to 200 kilometres, or even more, while the period of the waves may range from 5 to more than 90 minutes. The height or amplitude of a tsunami wave above the ocean surface may be from several centimetres to about a metre only - this also depending on the generating source. It is for these features that a tsunami is ordinarily not perceptible aboard a ship or trawler in the open ocean, when it passes under the vessel.

\section{GENERATION OF TSUNAMI. [1--5]}

The Greek historian Thucydides (460-395 BC) was the first to make an investigation of tsunamis in around $426 \mathrm{BC}$. He perceived correctly that the cause of generation of a tsunami might be an undersea earthquake --- the typical sequence of a tsunami being an initial earthquake, the sudden retreat of a sea and a following gigantic wave rushing towards the shore.

When a vast area of the ocean floor abruptly rises and falls through several metres, great impulsive disturbances are created which displace a large amount of water from its state of equilibrium in a very short time and a tsunami over the ocean surface is generated. The process is investigated in the following.

\subsection{Tectonic Plate Movement and Under- Ocean Earthquake.}

The Earth's Lithosphere is composed of the earth's Crust and the solid uppermost layer of the Mantle lying below the crust. The lithosphere extends from the earth's surface to a depth of about $100 \mathrm{~km}$ (the crust extending up to $35 \mathrm{~km}$ downward and the mantle beginning at about $35 \mathrm{~km}$ below the surface).

Asthenosphere is the zone of the earth's mantle lying beneath the lithosphere. It is much hotter and much more soft than the lithosphere, and is extended from about 100 to $700 \mathrm{~km}$ below the surface.

The lithosphere is broken into about 12 large, separate, rigid blocks or plates, and several small plates, known as Tectonic Plates. The plates float and move relative to one another over the underlying asthenosphere in a process impelled by continuous loss of heat from the earth's interior. Lateral density variations in the mantle result in slow convection currents, which is believed to cause the relative lateral movements of the tectonic plates (and the vast continents that rest over them) at a rate of up to $10 \mathrm{~cm}$ per year. The plates interact with one another along their boundaries or edges, known as Faults.

The region (zone) on the earth where two tectonic plates converge (tend to meet), is called a "Subduction Zone", in which one plate 'subducts' (which means descends or slips or slides) under an adjacent one and is forced, or sinks due to gravity, into the underlying mantle. For instance, around and under the boundaries of the Pacific Ocean, the denser oceanic plates subduct under the surrounding continental plates. 
The majority of earthquakes and volcanic eruptions on the earth's surface take place along the faults of tectonic plates. Tectonic Earthquakes, or Subduction Earthquakes, give rise to the earth's crustal deformation, and these earthquakes, when take place under an ocean, become particularly effective in producing tsunamis.

An under-ocean earthquake along a subduction zone may occur when one tectonic plate subducts under another. This movement goes on for decades or even centuries. If there is a "sticking point", that is, an obstruction to the motion, it slowly builds up large stress. Then, stuck to the subducting plate, the leading edge of the overriding plate suddenly breaks free and springs upward, raising the ocean floor and causing high vertical upward-downward movements of the floor along the two plate boundaries, and thus greatly disturbs the large volume of overlying water.

\subsection{Under-Ocean Earthquake and Generation of Tsunami.}

A tsunami can originate when violent earthquakes, occurring at the bottom of the ocean, suddenly distorts wide extent of the ocean floor causing massive vertical disturbance in the column of water lying over it.

\subsubsection{Mechanism of Tsunami Generation.}

(a) When a large under-ocean earthquake causes a vast region of the ocean bed to rapidly move several metres vertically upward and downward, a huge thrust acts upon the column of water standing over the disturbed area, which is compressed by the raised sea floor and then gets rarefied as the seafloor falls; the water column is again thrust upward, becomes compressed and again gets rarefied, with successive rise-and-fall of the seafloor. Thus, the enormous disturbance created at the bottom of the ocean proceeds upward as a longitudinal elastic water wave. Since water is practically incompressible, the speed of the longitudinal waves in sea water is very high ---around $1.7 \mathrm{~km} / \mathrm{sec}$--- and therefore, it takes for this disturbance only about $2.5 \mathrm{sec}$ to reach the surface of the ocean, the average depth of the deep ocean being about $4-5 \mathrm{~km}$.

(b) Then the open sea surface, vertically on top of the active area of the seafloor, is pushed up above the surrounding ocean surface by the energy of the upward moving longitudinal water wave. The large volume of water that is raised above the surrounding ocean surface takes the appearance of a "gigantic mound or hillock" on the sea surface. This huge mass of elevated sea water pulls up the water adjacent to it; then it begins to subside under gravity, pushing up the surrounding sea water; the uplifted sea water then falls down pushing up the sea water around it, and the process continues till the tumultuous movement of the seafloor goes on.

(c) A series of great waves, transverse waves of very long wavelength, propagating over the ocean surface --- a tsunami --- is thus set into motion, caused by the successive rise-and-fall of the great "hillock of water" above the ocean surface surrounding it. 
This is the mechanism of generation of a tsunami, produced by a violent underocean earthquake. The transition sequence, "From a large submarine earthquake to a great tsunami on the ocean surface," is however an intricate physical process which depends on the dimensions and magnitude of the deformation of the seafloor brought about by the earthquake, and also on the topography of the nearby landmass.

The tsunami waves thus generated propagate in all directions over the open ocean surface at great speeds depending on the depth of ocean and may reach transoceanic coastlines thousands of kilometres away from the source of generation.

\subsubsection{Energy of the Tsunami.}

The energy carried by the longitudinal elastic water waves moving upward may be estimated approximately from that of the gigantic "mound or hillock of water" that rises on the ocean surface. When the mound of water ceases to rise and attains its maximum elevation above the ocean surface, its energy is entirely potential, for before rising, it was in buoyant equilibrium with the surrounding sea surface. If, for simplicity, the shape of the hillock of water is assumed to be somewhat like that of a rectangular parallelepiped of volume, say $V$, and height, say $z$ (greatest vertical elevation of the sea surface), then the total energy (potential), say $E_{H}$, stored in this hillock-like water-mass is given by

$$
E_{H}=g \rho V . z / 2
$$

( $\rho$ being the mass-density of water and $g$ the standard acceleration due to gravity), since the centre of mass of this water-mass is lifted to a height $z / 2$ from the sea surface.

As this huge mound or hillock of water subsides to the level ocean surface, almost all of its energy $E_{H}$ is used up to generate great surface waves over the ocean --- the tsunami. With each rise-and-fall of this hillock of water, an amount of energy $E_{H}$ is transferred to the wave trains of the tsunami generated.

\subsection{Tsunamis Generated by Volcanoes, Landslides and Cosmic Collisions.}

A violent under-ocean volcanic eruption may exert massive impulsive forces and thereby induce great impulsive disturbances on the overlying water column; the disturbances then move vertically upward as a longitudinal elastic wave raising above the ocean surface a huge hillock of water, rapid upward-downward movement of which may generate transverse waves of long wavelength --- a tsunami--- over the ocean.

Submarine landslides are often caused by violent earthquakes and also by the collapse of undersea volcanic edifices. As huge amounts of sediment and rocks slump down and move across the sea floor, such under water landslides can greatly disturb the overlying water, and as a result, agitate the equilibrium sea level to such an extent that 
massive transverse waves on the surface --- a tsunami --- may be created.

Supermarine landslides and Cosmic body impacts on the ocean surface can immensely perturb the sea water from above, as the momentum and energy (kinetic) of the falling rocks and debris, or of the striking meteorites, are transferred to the sea water on which they fall, and as a consequence, great transverse waves over the ocean --- tsunamis --- may be generated.

Unlike ocean-wide tsunamis produced by major undersea earthquakes, tsunamis created by non-seismic mechanisms usually dissipate soon and seldom reach coastlines far from the area of the source of generation.

\section{PROPAGATION OF TSUNAMI. [5, 6]}

The wavelengths of tsunamis propagating on the open ocean surface, are usually over $150 \mathrm{~km}$, and therefore, far exceed the depth of the ocean, which is about 4 to $5 \mathrm{~km}$ only. Again, the speed of a long progressive wave (with wavelength much greater than the water depth) is known to be directly proportional to the square root of the water depth [6]. Thus, the tsunami wave speed increases as the depth of ocean increases.

Further, in a progressive surface wave, the effect of viscosity of the liquid is inversely related to its wavelength and this effect reduces to zero for large values of the wavelength, and hence also the rate of loss of energy (dissipation of energy due to viscosity) by the wave [6]. A tsunami having a very great wavelength, therefore, loses little energy during its propagation.

Hence, in deep ocean, a great tsunami can travel at high speeds for long periods of time across thousands of kilometres of transoceanic distances with very little loss of energy in the process, the deeper the ocean the greater being the speed.

At the deepest ocean depths, the tsunami speed comes about to be as much as 700 to $850 \mathrm{~km} / \mathrm{hr}$. The average depth of the deepest Pacific Ocean is $4.5 \mathrm{~km}$ and the tsunami speeds across the Pacific have been observed to be 700 to $800 \mathrm{~km} / \mathrm{hr}$. Thus, tsunamis can move from one side of the Pacific Ocean to the other side in less than one day.

\section{TSUNAMI AS SHALLOW-WATER WAVE.[7, 8]}

Tsunamis are characterised as shallow-water waves. A surface wave is regarded as a shallow-water wave, when the ratio of the water depth $h$ to the wavelength $\lambda$ gets very small. In general, the inequality

$$
h / \lambda<1 / 20
$$

is taken to characterize a shallow-water wave. Now, although tsunamis (which are small in amplitude, the wave height $a \leq 1$ metre only) travel over very deep water in the ocean, it is because of their extremely long wavelengths (much greater than the ocean depth, since $\lambda \approx 150$ to $200 \mathrm{~km}$ and $h \approx 4$ to $5 \mathrm{~km}$ ), that the ratio $h / \lambda$ becomes 
quite small:

$$
\begin{aligned}
& h / \lambda \approx 4 / 200 \text { to } 5 / 150 \\
& \text { i.e., } \approx 1 / 50 \text { to } 1 / 30 .
\end{aligned}
$$

Thus, tsunamis behave essentially, and can therefore be treated mathematically, as "Small amplitude water waves on the surface of shallow water".

In case of shallow water or long waves, i.e. where the water depth $h$ is small, or the wavelength $\lambda$ is large, the wave speed $c$ is known to be given by [6]

$$
c=\sqrt{g h},
$$

where $g$ is the acceleration due to gravity. Eq.(2), therefore, gives the speed of a tsunami travelling on the surface of an ocean of average depth $h$. As a tsunami eventually enters from the deep water of the open ocean into comparatively shallow water near the coastline, it undergoes a major transformation. This phenomenon is very significant and requires special attention.

\section{TSUNAMI CLOSE TO THE COASTLINE. [5, 8--10]}

When a tsunami arrives near a coastline, where the depth of water gradually diminishes towards the shore, both the wave speed and wavelength are observed to decrease, while the wave amplitude is observed to increase. Due to this shoaling (i.e., shallow water) effect, a tsunami, which is not felt over deep mid-ocean, may rise to several metres in height above the sea level near the coast. A large tsunami may crest to a greatest vertical height on the shore, called "run-up" height, of up to 40-45 metres or even more, above the sea level [5].

Although Eq.(2) accounts for the diminution in the wave speed as the tsunami approaches the shoreline, it does not, apparently, account for the observed diminution in the wavelength and the immense increase in the wave amplitude. A physical explanation for this phenomenon is presented in the following.

\subsection{Rise of the Ocean: Physical Explanation.}

Since a tsunami is a series of very long (over $150 \mathrm{~km}$ ) waves in the ocean, as the waves come closer to the coast, the depth of water beneath even half of the wavelength ( $75 \mathrm{~km}$ or more) does not remain the same; it diminishes gradually towards the shore. Thus, the front portion of a single advancing (towards the shore) wave crest moves on water, which is shallower than the water under its rear portion. Therefore, according to Eq.(2), the forward part of the crest proceeds slower than its backward part. As a result the wave crest gets compressed, so that the wavelength is reduced, and in consequence, the wave amplitude increases like an enormous hump. 
6. RISE OF THE OCEAN: Mathematical Explanations. [5, 6, 10 -14]

We now look for a suitable mathematical explanation for the gigantic rise of the ocean surface, as a tsunami comes close to a shore.

Let $a$ be the wave amplitude, $c$ the wave speed and $\lambda$ the wavelength of a surface wave travelling over a depth $h$ of the ocean. Then the energy-flux (rate of transmission of energy) is known to be $\frac{1}{2} g \rho a^{2} c$ and the energy-content per wavelength is $\frac{1}{2} g \rho a^{2} \lambda$, where $g$ is the acceleration due to gravity and $\rho$ the density of water.[6]

Let us consider the case of a tsunami that reaches close to the coastline, where the depth of water is about 50 meters, i.e. $h \approx 50 \mathrm{~m}$. It has been observed that the wave velocity $c<80 \mathrm{~km} / \mathrm{hr}$, and that the wavelength $\lambda<20 \mathrm{~km}$, the period $T$ of the wave being a little less than 15 minutes. It also has been observed that the wave amplitude swells greatly: $a>30 \mathrm{~m}$.[5]

For a mathematical account of this huge increase in the wave amplitude we may proceed as follows:

Let $a_{1}, a_{2}$ be the amplitudes, $\lambda_{1}, \lambda_{2}$ the wavelengths and $c_{1}, c_{2}$ the wave velocities of a tsunami wave at two different depths $h_{1}, h_{2}$ of the ocean. At first we consider two explanations which are ordinarily used.

6.1 An Usual Explanation. For the rise of the ocean surface near the shore when a tsunami approaches the shore, this explanation is based on:

Conservation of energy-flux of the wave: This means

$$
\begin{aligned}
& 1 / 2 g \rho a^{2} c=\text { constant, } \\
& \text { or } a^{2} \sqrt{g h}=\text { const. [ by Eq.(2) ] } \\
& \text { or } \\
& a^{2} \sqrt{h}=\text { const. }
\end{aligned}
$$

This relation shows that

or

$$
\begin{aligned}
& a_{1}^{2} \sqrt{h_{1}}=a_{2}^{2} \sqrt{h_{2}} \\
& a_{1}{ }^{2} / a_{2}^{2}=\sqrt{ }\left(h_{2} / h_{1}\right) .
\end{aligned}
$$

Let $h_{2}=4.5 \mathrm{~km}$ (average depth of the Pacific Ocean) and $a_{2}=1 \mathrm{~m}$. Then, for

$$
h_{1} \approx 50 \mathrm{~m}, 5 \mathrm{~m} \text { and } 1 \mathrm{~m} \text {, respectively, }
$$

we obtain

$$
a_{1} \approx 3 \mathrm{~m}, 5.5 \mathrm{~m} \text { and } 8.2 \mathrm{~m} \text {. }
$$


6.2 Another Common Explanation. This is based on:

Conservation of energy-content per wavelength: This means

$$
\begin{aligned}
1 / 2 g \rho a^{2} \lambda & =\text { constant } \\
a^{2} \lambda & =\text { const. }
\end{aligned}
$$

or

The relation is known as Green's Law. This gives

$$
\text { or } \quad a_{1}{ }^{2} / a_{2}^{2}=\lambda_{2} / \lambda_{1} \text {. }
$$

As in Sub-Sec.6.1, let $h_{2}=4.5 \mathrm{~km}, a_{2}=1 \mathrm{~m}$, and also let $\lambda_{2}=200 \mathrm{~km}$. Then, for

$$
h_{1} \approx 50 \mathrm{~m}, 5 \mathrm{~m} \text { and } 1 \mathrm{~m} \text {, respectively, }
$$

it is usually observed that [5]

$$
\lambda_{1} \approx 19.5 \mathrm{~km}, 2.5 \mathrm{~km} \text { and } 1 \mathrm{~km} \text {, nearly, }
$$

and therefore, we obtain

$$
a_{1} \approx 3.2 \mathrm{~m}, 9 \mathrm{~m} \text { and } 14.5 \mathrm{~m} .
$$

It is then seen that neither of the above two explanations is capable of accounting for a rise of the ocean surface more than $15 \mathrm{~m}$, while great tsunami waves are often observed to rise over 40-45 metres. We are then in need of a mathematical account for the increase of over $40-45 \mathrm{~m}$ in the tsunami wave amplitude. This is given in the following Sub-Section.

\subsection{A Third Explanation.}

Here, we turn to the usual dispersion relation for progressive waves of small amplitude on the surface of water of arbitrary depth, say $h$. This relation is known to be [6]

$$
\omega^{2}=g k \tanh k h,
$$

so that the wave velocity $c(=\omega / k)$ is given by

$$
c^{2}=(g / k) \tanh k h,
$$

where $k(=2 \pi / \lambda)$ is the wave number and $\lambda$ is the wavelength. In case of shallow water, or long waves, i.e. where $h$ is small, or $\lambda$ is large, we have $\tanh k h=k h$, so that $\mathrm{Eq}(6)$ reduces to

$$
c=\sqrt{g h},
$$

which has already been given in Sec.4. We now consider a modified form of the usual dispersion relation, $\mathrm{Eq}(5)$.

6.3.1 Amplitude-Dependent Dispersion Relation. [11,12]

A modified form of the dispersion relation, $\mathrm{Eq}(5)$, which incorporates the wave 
amplitude $a$, had been derived by this author in a previous investigation [11], and it is the following:

$$
\omega^{\prime 2}=g k \tanh k h \cdot\left(1-1 / 2 \cdot a^{2} k^{2} \operatorname{sech}^{2} k h\right),
$$

where the wave amplitude $a$ is small.

In case of shallow water, or long waves, we have

$\tanh k h=k h$ and $\operatorname{sech} k h=1$,

so that the amplitude-dependent dispersion relation, viz. Eq.(7), reduces to

$$
\omega^{\prime 2}=g k^{2} h\left(1-1 / 2 \cdot a^{2} k^{2}\right) .
$$

From Eq.(8) we obtain the wave velocity, say c', as

or

$$
\begin{aligned}
& c^{\prime}=\omega^{\prime} / k=\sqrt{g h}\left(1-1 / 2 \cdot a^{2} k^{2}\right)^{1 / 2} \\
& c^{\prime}=\sqrt{g h}\left(1-\pi^{2} a^{2} / \lambda^{2}\right)=c\left(1-\pi^{2} a^{2} / \lambda^{2}\right),
\end{aligned}
$$

neglecting $a^{4}$ and higher powers. It follows from the $\mathrm{Eq}(9)$ that

$$
c^{\prime}<\sqrt{g h}=c,
$$

and that $c^{\prime}$ decreases as the water depth $h$ decreases, and also as the ratio $a$ / $\lambda$ increases, i.e., as the wave amplitude increases, or the wavelength decreases, or both.

Now, for a tsunami wave in the open ocean the amplitude $a$ is small and wavelength $\lambda$ is large, so that $a / \lambda<<1$, and therefore, the term $\pi^{2} a^{2} / \lambda^{2}$ in the amplitudedependent dispersion relation, $\mathrm{Eq}(9)$, remains negligible until the tsunami enters shallow water near the coast, where it is observed that the wavelength diminishes and the amplitude increases. Hence, the $\mathrm{Eq}(9)$ becomes significant only when the tsunami wave enters shallow water near the shoreline.

\subsubsection{Shallow Water Effect.}

Let a tsunami be travelling over shallow water towards the coastline. Let $h$ be the depth of water below the wave crest proceeding towards the shore. Then it has been seen [Sec.4] that the velocity of the crest is given by

$$
c=\sqrt{g h} .
$$

As the tsunami reaches near the shoreline, where the depth of water gradually decreases towards the shore, the wave velocity is observed to decrease. This is in agreement with the $\mathrm{Eq}(2)$. However, the $\mathrm{Eq}(2)$ is incapable of accounting for the observed diminution in the wavelength and the huge increase in the wave amplitude, as the tsunami approaches the coast.

Now the front portion of the wave crest travels over water of depth $<h$ and the rear portion over water of depth $>h$. Let $h-y$ and $h+y$ be the corresponding depths of water, where $y<h$. Then, if $c_{1}$ and $c_{2}$ be the wave velocities at the depths $h--y$ and 
$h+y$, respectively, and $c_{o}$ the average velocity of the wave crest, we have by $\operatorname{Eq}(2)$

and

$$
c_{1}=\sqrt{[g(h-y)]}=\sqrt{g h}(1-y / h)^{1 / 2}
$$

$c_{2}=\sqrt{[g(h+y)]}=\sqrt{g h}(1+y / h)^{1 / 2}$,

so that

$$
\begin{aligned}
c_{1}+c_{2} & =\sqrt{g h}\left[(1-y / h)^{1 / 2}+(1+y / h)^{1 / 2}\right] \\
& =2 c\left[1-(1 / 8)(y / h)^{2}\right], \quad\left[\text { neglecting }(y / h)^{4}, \text { since } y / h \text { is small }\right],
\end{aligned}
$$

and therefore

$$
c_{o}=\left(c_{1}+c_{2}\right) / 2=c\left[1-(1 / 8) y^{2} / h^{2}\right]<c .
$$

It is then found that the average velocity $c_{o}$ of the wave crest, as given by the $\operatorname{Eq}(11)$, is less than the velocity $c$ of the crest, as given by the $\mathrm{Eq}(2)$. Again, the velocity $c$ ', as given by the $\operatorname{Eq}(9)$, is a little less than the wave velocity $c$ given by $\operatorname{Eq}(2)$, and the $\mathrm{Eq}(2)$ contains no term involving the amplitude $a$ and the wavelength $\lambda$. Hence, it would be more appropriate to use the $\operatorname{Eq}(9)$, rather than the $\mathrm{Eq}(2)$, for the expression for the average velocity of the wave crest near the shore.

Therefore, rewriting the amplitude-dependent dispersion relation, $\mathrm{Eq}(9)$, in the form:

$$
a=(\lambda / \pi)\left(1-c^{\prime} / \sqrt{g h}\right)^{1 / 2}=(\lambda / \pi)\left(1-c^{\prime} / c\right)^{1 / 2},
$$

the expression for the wave amplitude $a$ is obtained as

where

$$
\begin{gathered}
a=\frac{\lambda}{\pi \sqrt{c}} \sqrt{\Delta c}, \\
\Delta c=c-c \\
c^{\prime}(\text { very small })>0 .
\end{gathered}
$$

The Eqs(12) \& (13) show that for given values of $\lambda$ and $c$ (i.e. for given $h$ ), the wave amplitude $a$ increases with $\Delta c$, which is the difference between the values of the wave velocities $c$ and $c^{\prime}$ given by $\mathrm{Eq}(2)$ and $\operatorname{Eq}(9)$, respectively. have then

Now, coming back to the case where $h \approx 50 \mathrm{~m}$, we at first employ $\operatorname{Eq}(2)$. We

$$
\begin{aligned}
c=\sqrt{g h}=\sqrt{\left(9.8 \mathrm{~m} / \mathrm{s}^{2} \times 50 \mathrm{~m}\right)} & =22.1359 \mathrm{~m} / \mathrm{s}=79689 \mathrm{~m} / \mathrm{hr} \\
& =79.69 \mathrm{~km} / \mathrm{hr}<80 \mathrm{~km} / \mathrm{hr} \text { (observed). [5] }
\end{aligned}
$$

The period of the wave being observed to be a little (say about 15-20 sec.) less than $15 \mathrm{~min}$., by taking $T=14 \mathrm{~min} 42 \mathrm{sec}$, we obtain

$$
\lambda=c T=22.1359 \mathrm{~m} / \mathrm{s} \times 882 \mathrm{~s}=19524 \mathrm{~m}=19.52 \mathrm{~km}<20 \mathrm{~km} \text { (observed). [5] }
$$

Then taking

$$
\lambda=19525 \mathrm{~m} \text { and } c=79689 \mathrm{~m} / \mathrm{hr} \text {, }
$$

we get

$$
\begin{aligned}
\lambda /(\boldsymbol{\pi} \sqrt{c}) & =19525 /(3.1416 \times 282.2924) \\
& =\mathbf{2 2 . 0 2} \text { (numerically). }
\end{aligned}
$$

Therefore, we can write 


$$
a=22.02 \times \sqrt{\Delta c} .
$$

Now, setting gradually increasing values of $\Delta c$, beginning from $\Delta c=.05 \mathrm{~m} / \mathrm{hr}$ (which is hardly measurable), we derive the corresponding values of the wave amplitude $a$ by using the Eq(15). These are presented in the following table:

Table 1: Amount of Diminutions in the Wave Velocity $c$ and Corresponding values of the Wave Amplitude $a$.

\begin{tabular}{|c|c|c|c|c|c|}
\hline $\mathbf{S} / \mathbf{N}$ & $\begin{array}{c}\Delta c \\
\text { (in } \mathbf{~ m} / \mathbf{h r})\end{array}$ & $\begin{array}{c}\text { Amp } \boldsymbol{a} \\
\text { (in m) }\end{array}$ & $\mathbf{S} / \mathbf{N}$ & $\begin{array}{c}\Delta \boldsymbol{c} \\
\text { (in m/hr) }\end{array}$ & $\begin{array}{c}\text { Amp } \boldsymbol{a} \\
\text { (in m) }\end{array}$ \\
\hline 1 & 0.05 & 4.9 & 12 & 2.00 & 31.1 \\
\hline 2 & 0.10 & 7.0 & 13 & 2.25 & 33.0 \\
\hline 3 & 0.15 & 8.5 & 14 & 2.50 & 34.8 \\
\hline 4 & 0.20 & 9.8 & 15 & 2.75 & 36.5 \\
\hline 5 & 0.25 & 11.0 & 16 & 3.00 & 38.1 \\
\hline 6 & 0.50 & 15.6 & 17 & 3.50 & 41.2 \\
\hline 7 & 0.75 & 19.1 & 18 & 4.00 & 44.0 \\
\hline 8 & 1.00 & 22.0 & 19 & 4.50 & 46.7 \\
\hline 9 & 1.25 & 24.6 & 20 & 5.00 & 49.2 \\
\hline 10 & 1.50 & 27.0 & 21 & 5.50 & 51.6 \\
\hline 11 & 1.75 & 29.1 & 22 & 6.00 & 54.0 \\
\hline
\end{tabular}

This table shows that even very small diminutions in the values of the wave velocity $c$ (which, as already seen, actually occur for the average velocity of the wave crest when approaching the shore), give rise to the enormous increase in the values of the wave amplitude.

We thus see that using the amplitude-dependent dispersion relation, Eq.(9), it is possible to account for a tsunami run-up height of well over 50metres, on shore above the sea level, as the tsunami comes close to a shore. The factor $\left(1-\pi^{2} \frac{a^{2}}{\lambda^{2}}\right)$ in the Eq.(9) becomes significant only after the tsunami arrives on shallow water near the shore, when the wavelength begins to diminish, and at the same time, the wave amplitude begins to increase.

\subsection{Tsunami Encountering a Coastline Land.}


Some tsunamis have wave crests advancing first towards the coast and some have troughs moving first. In case of a tsunami propagating with a trough in front of the wave train, the water along the shoreline suddenly recedes inward the sea, exposing large area of the seabed, which normally remains submerged. The sea is said to be "driven back" or to 'withdraw', the phenomenon being known as "drawback of the sea", sometimes even accompanied by a sucking sound.

When a tsunami finally encounters a coastline land, it crashes with enormous force inundating vast expanses of the shore, extending inland up to several hundreds of metres, and causes thereby, widespread devastation and loss of lives on the land.

\section{DISCUSSION}

Great tsunamis are usually generated by catastrophic underwater events like violent under-ocean earthquakes or volcanic eruptions, or by massive undersea landslides. Of all such events, relatively frequent is the under-ocean earthquake. Very strong earthquakes of magnitude greater than 9.0 in the Gutenberg-Richter Scale usually take place once in 10 years or more. Most, if not all, under-ocean earthquakes are caused by massive undulations of tectonic plates along their convergent boundaries (faults).

The geological process 'subduction' takes place at convergent edges of tectonic plates where one plate subducts under an adjacent one, and then into the underlying mantle. The rates of subduction are measured in centimetres per year, the average rate of convergence of the tectonic plates being approximately 2 to $8 \mathrm{~cm} / y \mathrm{r}$ along most plate boundaries. Subduction phenomena are known to produce the strongest earthquakes on earth, called "megathrust earthquakes".

Potential tsunami locations on earth are at the subduction zones. Most of the tsunamis are generated by earthquakes occurring at subduction zones. The two great earthquakes of the 21st century, viz. the great Sumatra-Indonesian Earthquake in 2004 and the great East Japan Earthquake in 2011, as well as most of the large earthquakes of the last two centuries, were triggered by subduction of tectonic plates, and almost all of them gave rise to widespread devastating tsunamis.

The two tectonic plates, viz., the India Plate and the Burma Plate, meet each other at the undersea Sunda Trench near North Sumatra. The great Sumatra-Indonesian Earthquake and the resulting great Indian Ocean Tsunami that took place on Sunday, December 26, 2004, were caused by the subduction of the India Plate under the Burma Plate.

The tectonic Eurasian Plate and the Pacific Plate converge to each other at the undersea Japan Trench offshore of East Japan. The great East Japan Earthquake and the consequent great tsunami over the Pacific Ocean surface that occurred on Friday, March 11, 2011, were caused by the subduction of the Pacific Plate under the Eurasian Plate.

Man can make extensive investigations in what exists surrounding the earth's crust, viz. the atmosphere; but cannot make similar intensive studies of what lies under the 
crust. As a result, although scientists can make weather forecasts with good precision, they cannot do the same in case of earthquakes and tsunamis. Science cannot yet predict exactly where and when the next earthquake will occur, or a volcano will erupt under-ocean, or where will take place a massive undersea landslide, and as such, it is not yet possible to predict where and when on earth the next tsunami will be generated. Using historical records and numerical models of tsunamis, as well as by extensive geophysical investigations, scientists can, at the most, have an idea as to where this deadly calamity of nature is more likely to strike.

\section{ACKNOWLEDGEMENTS}

It is a pleasure to offer my grateful thanks to Prof. K.K. Das, Prof. P.R. Ghosh and Prof. S.K. Chakraborty for their valuable suggestions and helpful discussions on the work. I also wish to thank Mr. B. Dev, college student, Dr. P. Mukherjee, physician and Mr. B. Raj, engineer, for fruitful discussions easily understandable by nonspecialist general readers.

\section{REFERENCES}

[1] U. S. National Oceanic and Atmospheric Administration (NOAA), 1994. "Tsunami, The Great Waves."

[2] Britannica Ready Reference Encyclopaedia, 2005. - Plates Tectonics, Subduction Zones.

[3] United States Geological Survey (USGS), 2005. - Information about Tsunamis and Earthquakes.

[4] Synolakis, C., Liu, Ph., Carrier, G. and Yeh, H.,1997. — "Tsunami-genic Sea Floor Deformations", Science, 278, 598-600.

[5] Wikipedia: The Free Encyclopaedia. - General description of Earthquake and Tsunami.

[6] Lamb, H.,1975. - Hydrodynamics, 6th Ed. Cambridge Univ. Press, pp. 367, 640-641.

[7] Lautrup, B.,2005. - Physics of Continuous Matter, Chap. 24, The Niels Bohr Institute, Institute of Physics Publishing, University of Copenhagen, Denmark.

[8] Craig , W., 2005. - "Surface Water Waves and Tsunamis", Dynamics of Surface Water Waves, Department of Mathematics and Statistics, McMaster University, Hamilton, Ontario, Canada.

[9] Van Groesen, E. and Klopman. G., July, 2005. - "Dispersive effects in tsunami generation", Proceedings of the Workshop on Indonesian Ocean Tsunami, Bali, Indonesia .

[10] Levin, B. and Nosov, M., 2009. - Physics of Tsunamis, Springer, 
Netherlands.

[11] Barman, S.K., 2009. -“A new amplitude-dependent form of the dispersion relation in progressive surface waves of small amplitude", Indian Journal of Theoretical Physics, 57(2), 131-136.

[12] Barman, S.K. ,2011. - "Tsunami and rise of the ocean surface near the shore: application of an amplitude-dependent dispersion relation", Indian Journal of Theoretical Physics, 59(1), 65-73.

[13] Web pages --- U.S. National Weather Service: International Tsunami Information Centre.

[14] Web pages --- Russian Tsunami Laboratory, Novosibirsk. 